\title{
BMJ Open Rating of four different foods in women with hyperemesis gravidarum: a randomised controlled trial
}

\author{
Gi Ni Tan, Peng Chiong Tan, Jesrine Gek Shan Hong (D) , Balaraman Kartik, \\ Siti Zawiah Omar
}

To cite: $\operatorname{Tan} \mathrm{GN}$, Tan PC, Hong JGS, et al. Rating of four different foods in women with hyperemesis gravidarum: a randomised controlled trial. BMJ Open 2021;11:e046528. doi:10.1136/ bmjopen-2020-046528

- Prepublication history and additional supplemental material for this paper are available online. To view these files, please visit the journal online (http://dx.doi.org/10.1136/ bmjopen-2020-046528).

Received 03 November 2020 Revised 03 April 2021 Accepted 26 April 2021

A) Check for updates

(c) Author(s) (or their employer(s)) 2021. Re-use permitted under CC BY-NC. No commercial re-use. See rights and permissions. Published by BMJ.

Obstetrics and Gynaecology, University of Malaya, Kuala Lumpur, Malaysia

Correspondence to Dr Jesrine Gek Shan Hong; jesrine@um.edu.my

\section{ABSTRACT}

Objective To evaluate four foods in women with hyperemesis gravidarum $(\mathrm{HG})$ on their agreeability and tolerability.

Design Prospective, randomised, within-subject crossover trial.

Setting Single-centre, tertiary, university hospital in Malaysia.

Participants 72 women within 24-hour of first admission for $\mathrm{HG}$ who were 18 years or above, with confirmed clinical pregnancy of less than 16 weeks' gestation were recruited and analysed. Women unable to consume food due to extreme symptoms, known taste or swallowing disorder were excluded.

Interventions Each participant chewed and swallowed a small piece of apple, watermelon, cream cracker and white bread in random order and was observed for $10 \mathrm{~min}$ after each tasting followed by a 2 min washout for mouth rinsing and data collection.

Outcome measures Primary outcome was food agreeability scored after 10 min using an 11-point 0-10 Visual Numerical Rating Scale (VNRS). Nausea was scored at baseline (prior to tasting) and 2 and 10 min using an 11-point VNRS. Intolerant responses of gagging, heaving and vomiting were recorded.

Results On agreeability scoring, apple (mean \pm SD $7.2 \pm 2.4)$ ranked highest followed by watermelon $(7.0 \pm 2.7)$ and crackers $(6.5 \pm 2.6)$, with white bread ranked lowest (6.0 \pm 2.7$)$; Kruskal-Wallis $H$ test, $p=0.019$. Apple had the lowest mean nausea score and mean rank score, while white bread had the highest at both 2 and $10 \mathrm{~min}$; the Kruskal-Wallis $\mathrm{H}$ test showed a significant difference only at $10 \min (p=0.019)$ but not at $2 \min (p=0.29)$ in the ranking analyses. The intolerant (gagged, heaved or vomited) response rates within the 10 min study period were apple $3 / 72(4 \%)$, watermelon $7 / 72(10 \%)$, crackers $8 / 72(11 \%)$ and white bread $12 / 72(17 \%): \chi^{2}$ test for trend $\mathrm{p}=0.02$.

Conclusion Sweet apple had the highest agreeability score, the lowest nausea severity and intolerance-emesis response rate when tasted by women with $\mathrm{HG}$. White bread consistently performed worst.

\section{INTRODUCTION}

Hyperemesis gravidarum (HG), a condition characterised by intractable nausea and vomiting, affects about $0.3 \%-3.6 \%$ of

\section{Strengths and limitations of this study}

An original food taste trial in evaluating foods in women with hyperemesis gravidarum $(\mathrm{HG})$.

- The design and implementation of the trial which included the randomisation of the food taste sequence, washout period with mouth rinsing and small food amount alleviated the 'carryover effects' where the prior food tasted and volume of tasting might bias findings

- The four food items trialled were widely consumed and of limited to no variability in themselves, which should cut through any ethnicity-moulded food preparation or taste allegiance, hence support generalisability to other HG populations.

- Relatively small sample size and the trial was limited to four foods.

- Nausea outcomes could be considered hypothesis generating rather than definitive.

pregnant women ${ }^{1}$; the less severe nausea and vomiting of pregnancy (NVP) is exceedingly common such that by the eighth week of pregnancy, $57.3 \%$ of women had reported nausea without vomiting and $26.6 \%$ reported both nausea with vomiting. ${ }^{2}$ NVP should only be diagnosed when onset is in the first trimester of pregnancy and other causes of nausea and vomiting have been excluded. ${ }^{3}$ There is no consensus definition available for $\mathrm{HG}$; it is typically viewed as the severe form of NVP. ${ }^{4}$ HG can be diagnosed when there is protracted NVP with the triad of more than $5 \%$ prepregnancy weight loss, dehydration and electrolyte imbalance. ${ }^{3}$ As weight loss data can be unreliable or unobtainable, the need for hospitalisations in severe NVP can be used as criteria for $\mathrm{HG}^{5}{ }^{5}$

In our urban university hospital, the HG rate ranged from $2.3 \%$ to $3.9 \%$ of maternities. ${ }^{6}$ In a UK report on over eight million pregnant women, $1.5 \%$ were hospitalised for $\mathrm{HG} .^{7}$ These hospitalised women are at increased risk of adverse pregnancy outcomes such as anaemia, pre-eclampsia, eclampsia, 
venous thromboembolism, preterm and very preterm birth, caesarean birth, low birth weight or small for gestational age and neonatal intensive care. ${ }^{8} \mathrm{HG}$ is the second most common indication for hospitalisation in women with live births. ${ }^{9}$

The initial inpatient management for $\mathrm{HG}$ in our university hospital is intravenous rehydration, antiemetics and thiamine supplementation. ${ }^{10}{ }^{11}$ In the UK, hospital admissions and antiemetic prescribing increased continuously during 1998-2013 and focus on hospital admissions has greatly underestimated the burden of NVP. ${ }^{12}$ Many women described HG as one of their worst life experiences with profound morbidity and reported suboptimal management of HG and lack of support from healthcare professionals. ${ }^{13}$ Women affected by HG report not being taken seriously by caregivers, pressure for them to eat, lack of early intervention to prevent dehydration and the importance of a single room in the hospital to avoid stimuli that evoked vomiting, like light, noise and smells, in particular food, but also body odour and perfumes. ${ }^{14}$ Taste and smell capability are impaired in HG, with smell more affected, ${ }^{15}$ but how the impairments may impact food and drink tolerances is not known.

There is little published evidence regarding the efficacy of dietary changes for prevention or treatment of NVP. ${ }^{16}$ In pregnancy, sweet foods (eg, chocolates, sweets and biscuits), fruit juices and milk are commonly craved, ${ }^{17}$ while the most commonly reported aversions were for drinks containing caffeine and also spicy and fatty foods. ${ }^{18}$ A Finnish study reported that women with NVP consumed less meat and somewhat fewer vegetables than other pregnant women. ${ }^{19}$ There are opinions that eliminating coffee and spicy, odorous, ${ }^{20}$ high-fat, very sweet foods and substituting snacks or meals that are proteindominant, ${ }^{21}$ salty, low-fat, bland and dry (eg, crackers, cereal and toast) may help in $\mathrm{HG}^{22}$ Protein-predominant snacks are associated with decreased nausea in one study. ${ }^{23}$ It is suggested that fluids are better tolerated cold, clear, carbonated and sour (eg, ginger ale and lemonade) and taken in small amounts with a straw. ${ }^{24}$ Cracker is usually advised in HG. ${ }^{22}{ }^{25}$ A study done in our centre obtained questionnaire-based responses from patients with HG and found that fewer were likely to feel nauseated or want to vomit when they considered eating apples $(16 \%$, which topped the tolerated list), followed by watermelon (21\%), oranges $(23 \%)$, banana $(27 \%)$ and white bread $(31 \%)$ compared with eating green vegetables $(40 \%)$, papaya $(42 \%)$, chicken $(52 \%)$ and plain rice $(71 \%) .{ }^{15}$ The oft recommended dry cracker made $40 \%$ feel nauseated when they considered consuming them. The study also finds that imagined consumption of crunchy-textured and sweet foods was least likely to evoke a nauseous or vomit response. Direct testing of the same HG affected women in the same study with taste sticks showing that sweet taste is best and bitter taste worst tolerated. ${ }^{15}$

We evaluated the feasibility of our food taste trial design in women with $\mathrm{HG}$ and the empiric response towards four common foods including two, apple and watermelon, that topped our questionnaire for tolerability and to crackers and bread, which were often touted as tolerated foods in HG. The data might provide an evidence base to dietary advice in HG.

\section{MATERIALS AND METHODS}

The first participant was recruited on 9 January 2018 and the last on 3 July 2018.

\section{Participants}

Patients were recruited from the gynaecology ward where patients HG in our hospital were exclusively admitted to and were initially assessed for eligibility by scrutinising their medical records. Inclusion criteria were admission for HG (defined as presence of nausea and intractable vomiting sufficient to cause dehydration and metabolic disturbance of a severity to require hospitalisation, occurrence early in pregnancy), ${ }^{10}$ confirmed clinical pregnancy (at least a positive pregnancy test if an intrauterine gestational sac is not yet visible on ultrasound), gestation of less than 16 weeks, age 18 years old or older, and patient was within 24 hours of first admission for HG in their current pregnancy. Exclusion criteria included inability to participate or consume the food due to extreme symptoms, confirmed non-viable pregnancy, known taste or swallowing disorder and any allergies to foods tested.

Women who fulfilled the initial eligibility criteria were approached for trial participation. They were provided with a Patient Information Sheet and a verbal explanation of the study. All participants provided written informed consent. Each participant was interviewed by the investigator (GNT) and information obtained was transcribed to the Case Report Form. Food tasting was conducted by GNT in the ward.

\section{Trial design}

The trial was a within-subject design with three cross-overs to cover the four foods tasted. There were 24 possible permutations of the tasting order of the four foods. This 24 permutations list was recycled three times (order randomised for each cycle) to incorporate 72 participants (see further for sample size calculation). Random sequencing for the 24 permutations list was generated using random.org online software and prepared by coinvestigator PCT, who was not involved in enrolment. Each taste order permutation was inserted in individual sealed numbered envelopes. The envelopes were allocated strictly according to lowest available number and food order for tasting revealed only at the start of each experiment.

\section{Interventions}

Foods were prepared by the investigator (GNT) according to a standard operating protocol for food preparation and storage (refer to online supplemental appendix S1). 1. A slice of fresh red apple (weight approximately $20 \mathrm{~g}$, Fuji Apple). 
2. One slice of fresh red watermelon (weight approximately $20 \mathrm{~g}$ ).

3. A piece of fresh plain white bread $(1.0-1.5 \mathrm{~cm}$ thickness) with the crusts cut off (approximately $5 \times 5 \mathrm{~cm}$ in size).

4. Quarter piece of Jacob's Cream Crackers (manufacturer: Kraft Malaysia).

In the presence of the investigator, the participants chewed and swallowed the four foods in allocated sequence, then were observed for $10 \mathrm{~min}$ after each tasting. To alleviate the carry-over effect of a previously tasted food, tasting was conducted in the 24 food order permutations, recycled three times such that all foods had an identical order pattern in the trial.

Participants were required to rinse their mouth with plain water after each food item had been tasted and were allowed a 2 min rest period (for wash-out and collection of data) before they proceeded to the next food item. Water could be drunk at any time during the tasting.

If participants were unable to tolerate the food item or vomited, they were allowed to rest, then to continue with the tasting when able. Outcome forms were completed by participants and case report forms were completed by GNT on hospital discharge. Investigators were not blinded due to the nature of the intervention.

\section{Outcome measures}

Participants were asked to score the severity of their nausea with the use of a Visual Numerical Rating Scale (VNRS) scored from 0 to 10 (0, no nausea, to 10 , worst possible nausea). The scoring was done at baseline $(0$ min, just before food tasting), and 2 and 10 min (timed by stopwatch) after tasting of each food. Participants recorded if they had vomited, heaved or gagged during food tasting and the following $10 \mathrm{~min}$. Vomiting is defined as an act or instance of expulsing gastric contents through the mouth. ${ }^{26}$ Heaving, also known as retching, is a series of spasmodic muscular contractions without vomiting. ${ }^{26}$ Gagging is described as undergoing a regurgitative spasm in the throat as from revulsion to a food, smell or in reflexive response to an introduced object. ${ }^{27}$

After $10 \mathrm{~min}$, participants were asked to provide an agreeability score on the food tasted with the use of a VNRS scored from 0 to 10 (0, profoundly disagreeable, and 10 , most agreeable).

The primary outcome was the food agreeability score, while the secondary outcomes were the nausea scores at 2 and $10 \mathrm{~min}$ and the emesis-associated responses to the tasted food. We selected food agreeability score as the primary outcome as it was a holistic measure that encompassed the entire tasting experience from the participant's perspective, and the sample size calculated was powered to this outcome.

\section{Sample size}

Sample size for the trial was justified thus: with regard to the primary outcome food agreeability score, it was assumed that a 1-point VNRS mean difference (with an
$\mathrm{SD}$ of 2) between the foods existed and that the 1-point difference magnitude was meaningful to the participants. Applying $\alpha$ of 0.0083 (Bonferroni correction for six paired analyses) and power of $80 \%$ applying paired t-test for analysis, 52 participants were needed. The same rationale was used for the nausea score at 2 and $10 \mathrm{~min}$ analyses. We rounded up to 72 participants so that three complete cycles of the 24 different permutations of food sequence were accommodated.

\section{Statistical analysis}

Data entry and analysis were done using SPSS Statistics software V.25. Post hoc, the Kruskal-Wallis H test was used to rank food agreeability score, nausea score at baseline, 2 and $10 \mathrm{~min}$, the change in nausea score from baseline to 2 and to 10 min across the four tasted foods. Paired t-test was applied to analyse food agreeability score in six paired comparisons. $\chi^{2}$ for trend test was used to analyse the participants' emesis-associated responses towards the tasted foods in the ranks generated by agreeability scores and nausea scores. Student t-test was used to analyse normally distributed data.

\section{Patient and public involvement}

Patients or the public were not involved in the design, or conduct, or reporting, or dissemination plans of our research.

\section{RESULTS}

The recruitment flow of participants into the trial was displayed on figure 1. A total of 119 patients were admitted with $\mathrm{HG}$ during the trial recruitment period from 9 January 2018 to 3 July 2018. Seventy-three patients were approached; all but 1 agreed to participate. Enrolment was stopped when the targeted sample size of 72 was attained. Written consent was obtained from all participants. All participants completed the four-item food tasting trial according to their allocated food test sequences without a break from trial protocol.

Table 1 shows the characteristics of the trial participants. At hospitalisation, mean gestation was 9 weeks, with mean 7 days of nausea and vomiting reported, and two women carried twins. All (69) but three needed only the single agent intravenous metoclopramide, our standard first-line antiemetic, ${ }^{28}{ }^{29}$ during their hospitalisation.

Table 2 showed the food agreeability scores and analyses. Kruskal-Wallis $\mathrm{H}$ test showed a statistically significant result $(\mathrm{p}=0.019)$ in rank analysis, with apple ranked highest and bread lowest. Paired analysis that applied the Bonferroni corrected $\alpha=0.0086$ showed a significant difference between apple and bread $(\mathrm{p}=0.001)$ only; comparisons between apple and crackers $(\mathrm{p}=0.05)$ and watermelon and bread $(\mathrm{p}=0.026)$ were not significant for $\alpha=0.0086$.

Table 3 showed the nausea score at 10 and 2 min after food tasting and the relevant analyses. Kruskal-Wallis $\mathrm{H}$ rank test showed a significant difference at $10 \mathrm{~min}$ 


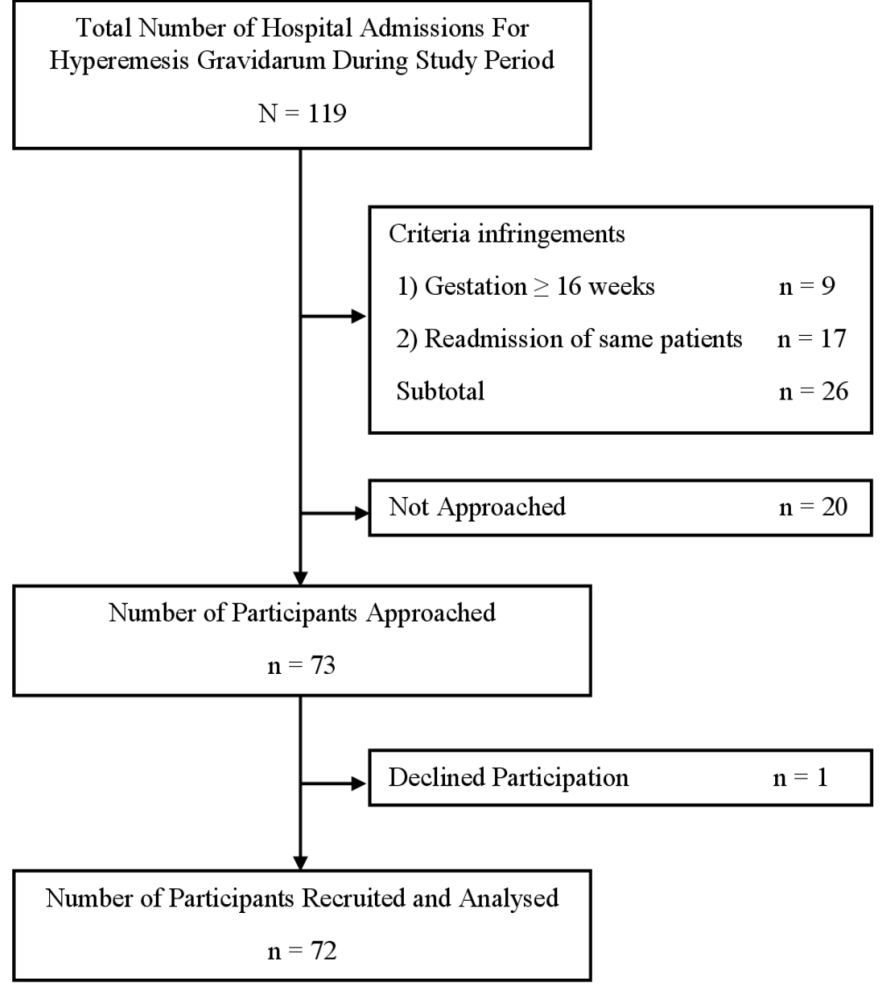

Figure 1 Recruitment flowchart of patients with hyperemesis gravidarum into the study.

( $\mathrm{p}=0.019$ ) with apple ranked lowest for nausea and bread highest. There was no significant difference at $2 \mathrm{~min}$ $(\mathrm{p}=0.29)$ and baseline $(\mathrm{p}=0.39)$. The baseline data vindicated our use of the 24 permutations food taste sequences.

As the change in nausea score from baseline to 2 and 10 min was fairly small and comparable in magnitude to baseline nausea score differences across trial arms, we performed post hoc analysis based on nausea score change from baseline to 2 and $10 \mathrm{~min}$. For this analysis, Kruskal-Wallis $\mathrm{H}$ rank test similarly showed a significant difference at $10(\mathrm{p}<0.001)$ but not $2 \mathrm{~min}(\mathrm{p}=0.068)$. At 10 min, watermelon had the lowest mean rank score of 122 , marginally lower than apple with mean rank of 125 , but apple had the lower $($ mean $\pm \mathrm{SD})$ nausea score at $10 \mathrm{~min}$ of $2.0 \pm 2.3$ vs $2.5 \pm 2.5$ for watermelon.

Table 4 showed results of the participants' intolerant response (gagged, heaved or vomited in order of severity, the most severe taken as the representative response) to the food tasted. Apple provoked the fewest intolerant responses $(3 / 72,4 \%)$ followed by watermelon $(7 / 72,10 \%)$, cracker $(8 / 72,11 \%)$ then bread with the most $(12 / 72,17 \%)$ $\left(\mathrm{p}=0.02, \chi^{2}\right.$ test for trend $)$, a significant trend.

Apart from the intolerant responses of gagging, heaving and vomiting during the tasting trial, there were no other important harms (eg, Mallory Weiss tears, haematemesis and allergic response) to participants.

\section{DISCUSSION}

This study showed a broadly consistent trend that the two fruits tested were more agreeable and better tolerated
Table 1 Characteristics of food taste trial participants hospitalised with hyperemesis gravidarum

\begin{tabular}{|c|c|c|}
\hline \multirow[b]{2}{*}{ Characteristics } & \multicolumn{2}{|l|}{$\mathrm{N}=72$} \\
\hline & n (\%) & Mean \pm SD \\
\hline \multicolumn{3}{|l|}{ Gestation } \\
\hline Singleton & $70(97)$ & \\
\hline Multiple pregnancy & $2(3)$ & \\
\hline \multicolumn{3}{|l|}{ Marital status } \\
\hline Single & $1(1)$ & \\
\hline Married & $71(99)$ & \\
\hline \multicolumn{3}{|l|}{ Education level } \\
\hline Up to secondary & $13(18)$ & \\
\hline Diploma & $36(50)$ & \\
\hline Degree and above & $23(32)$ & \\
\hline \multicolumn{3}{|l|}{ Occupation } \\
\hline Housewife & $9(13)$ & \\
\hline Paid & $62(86)$ & \\
\hline Unpaid & $1(1)$ & \\
\hline Age (years) & & $29.0 \pm 4.5$ \\
\hline 25 and below & $20(28)$ & \\
\hline $26-30$ & $24(33)$ & \\
\hline $31-35$ & $22(31)$ & \\
\hline Above 35 & $6(8)$ & \\
\hline Gestational age (weeks) & & $9.8 \pm 2.3$ \\
\hline Below 9 & $30(42)$ & \\
\hline $9-12$ & $31(43)$ & \\
\hline Above 12 & $11(15)$ & \\
\hline \multicolumn{3}{|l|}{ Ethnicity } \\
\hline Malay & $56(78)$ & \\
\hline Chinese & $5(7)$ & \\
\hline Indian & $9(12)$ & \\
\hline Others & $2(3)$ & \\
\hline Body Mass Index & & $23.3 \pm 4.8$ \\
\hline $15.0-19.9$ & $19(26)$ & \\
\hline 20.0-24.9 & $31(43)$ & \\
\hline 25.0-29.9 & $12(17)$ & \\
\hline $30.0-34.9$ & $9(13)$ & \\
\hline 35 and above & $1(1)$ & \\
\hline $\begin{array}{l}\text { Duration of nausea and } \\
\text { vomiting (days) }\end{array}$ & & $7.8 \pm 5.9$ \\
\hline 6 or fewer & $35(49)$ & \\
\hline $7-13$ & $19(26)$ & \\
\hline 14 or more & $18(25)$ & \\
\hline \multicolumn{3}{|l|}{ Parity } \\
\hline Nulliparous & $32(44)$ & \\
\hline Parous & $40(56)$ & \\
\hline
\end{tabular}

Continued 


\section{Table 1 Continued}

\begin{tabular}{ccc} 
& $\mathbf{N}=\mathbf{7 2}$ & \\
\cline { 2 - 3 } Characteristics & $\mathbf{n}(\%)$ & Mean \pm SD \\
\hline One antiemetic & $69(96)$ & \\
Two or more antiemetics & $3(4)$ & \\
\hline
\end{tabular}

Data expressed as number (\%) and mean \pm SD.

compared with bread and crackers in women hospitalised with HG. Apple was ranked the most agreeable food followed by watermelon, crackers with bread the least agreeable, a significant finding in rank. Apple also had the lowest mean nausea score and also ranked lowest in nausea score at 2 and $10 \mathrm{~min}$ after tasting, but the finding that was only significant at $10 \mathrm{~min}$. However, with regard to the change in nausea score, watermelon topped the list with the largest mean difference decline at $10 \mathrm{~min}$ that edged apple to second position, the rank finding was significant. These findings supported the findings generated from a questionnaire study from our centre that favoured fruits in women with HG. ${ }^{15}$

Recorded intolerant responses to the foods tasted also showed that apple had the fewest adverse responses (with no vomiting, the worst response) and bread the most, the trend analysis was significant at the $5 \%$ level and consistent with the agreeability and nausea score data.

A Norwegian study in women with NVP reported notable changes in diet and where NVP severity was positively correlated with consumption of white bread. ${ }^{30}$ NVP severity was negatively correlated with consumption of vegetables, tea and coffee, rice and pasta, breakfast cereals, beans and pulses and citrus fruits and fruit juices and positively correlated with consumption of white bread and soft drinks. ${ }^{31}$ However, in both these cross-sectional studies, the direction and causal relationship between severity of NVP and food intake could not be evaluated. Our data indicated that white bread had consistently the worst performance after tasting in agreeability, nausea response and actual physical (gagged, heaved or vomited) intolerant responses which supported the directional and plausibly causal relationship of white bread consumption to increased nausea and vomiting.

The Norwegian study also reported women with NVP had slightly higher intakes of fruit and vegetables compared with other pregnant women. ${ }^{30}$ Our finding in HG affected women that the two fruits were more agreeable and better tolerated provided support for the plausible rationale that NVP affected women might have trusted their instincts and experience and gravitated towards fruit consumption, but cultural influences across our populations may also play a part in food choices.

An earlier questionnaire-based response study from our centre studied the response of women with HG towards food tastes and textures and found that considering consuming sweet, crunchy food was least likely to evoke nausea or urge to vomit. ${ }^{15}$ In our study, we used Fuji apple, which is commonly described as a sweet and crisp apple variety, and our trial finding broadly supported the questionnaire's findings.

Dietary guidelines ${ }^{22} 32$ also suggested dry, starchy food in patients with $\mathrm{HG}$, with crackers, ${ }^{25}$ being a commonly suggested food. Our tasting trial could not support these recommendations as the two fruits, particularly apple, typically ranked better on the agreeability and tolerability comparisons.

Many women described HG as one of their worst life experiences with profound morbidity ${ }^{13}$ with repeat

Table 2 Food agreeability VNRS (0-10; high score, more agreeable) of a food tasting trial in women hospitalised for hyperemesis gravidarum

\section{(A) Ranked by Kruskal-Wallis H test}

\begin{tabular}{|c|c|c|c|}
\hline & \multicolumn{3}{|l|}{ Agreeability VNRS } \\
\hline & \multicolumn{2}{|l|}{ Median $(95 \% \mathrm{Cl})$} & $P$ value \\
\hline Apple & \multicolumn{2}{|l|}{$7.00(0.83$ to 10.00$)$} & 0.02 \\
\hline Crackers & \multicolumn{3}{|l|}{$7.00(0.00$ to 10.00$)$} \\
\hline Bread & \multicolumn{3}{|l|}{$6.00(0.00$ to 10.00$)$} \\
\hline & \multicolumn{3}{|c|}{ Difference in agreeability VNRS (pairwise comparisons) } \\
\hline & Watermelon & Crackers & Bread \\
\hline & Mean difference \pm SE & Mean difference \pm SE & Mean difference \pm SE \\
\hline Apple & $0.2 \pm 0.4$ & $0.7 \pm 0.3$ & $1.2 \pm 0.3$ \\
\hline Watermelon & & $0.5 \pm 0.4$ & $1.0 \pm 0.4$ \\
\hline
\end{tabular}

A: analysis by Kruskal-Wallis $\mathrm{H}$ test; $\mathrm{B}$ : analysis by paired t-test.

VNRS, Visual Numerical Rating Scale. 
Table 3 Secondary outcomes: nausea score by VNRS $(0-10)$ at baseline and 2 and 10 min after food tasting and mean change in nausea VNRS between baseline to 2 and 10 $\min$

\begin{tabular}{|c|c|c|c|}
\hline & \multicolumn{2}{|l|}{ Nausea VNRS } & \multirow[b]{2}{*}{$P$ value } \\
\hline & Mean \pm SD & Mean rank & \\
\hline \multicolumn{4}{|l|}{ At baseline } \\
\hline Apple & $2.4 \pm 2.2$ & 138 & 0.4 \\
\hline Watermelon & $2.9 \pm 2.3$ & 156 & \\
\hline Crackers & $2.3 \pm 2.0$ & 135 & \\
\hline Bread & $2.7 \pm 2.2$ & 149 & \\
\hline \multicolumn{4}{|l|}{ At 2 min } \\
\hline Apple & $2.0 \pm 2.1$ & 131 & 0.3 \\
\hline Watermelon & $2.5 \pm 2.2$ & 150 & \\
\hline Crackers & $2.3 \pm 2.3$ & 141 & \\
\hline Bread & $2.7 \pm 2.4$ & 156 & \\
\hline \multicolumn{4}{|l|}{ At $10 \mathrm{~min}$} \\
\hline Apple & $2.0 \pm 2.3$ & 116 & 0.02 \\
\hline Watermelon & $2.5 \pm 2.5$ & 134 & \\
\hline Crackers & $2.5 \pm 2.5$ & 137 & \\
\hline Bread & $2.9 \pm 2.7$ & 191 & \\
\hline & \multicolumn{3}{|c|}{ Change in nausea VNRS } \\
\hline & $\begin{array}{l}\text { Mean } \\
\text { difference } \pm S E\end{array}$ & Mean rank & $P$ value \\
\hline \multicolumn{4}{|l|}{ Baseline-2 min } \\
\hline Apple & $-0.43 \pm 0.16$ & 135 & 0.07 \\
\hline Watermelon & $-0.44 \pm 0.25$ & 130 & \\
\hline Crackers & $-0.01 \pm 0.20$ & 155 & \\
\hline Bread & $0.00 \pm 0.18$ & 159 & \\
\hline \multicolumn{4}{|c|}{ Baseline-10 min } \\
\hline Apple & $-0.40 \pm 0.23$ & 125 & $<0.001$ \\
\hline Watermelon & $-0.38 \pm 0.29$ & 122 & \\
\hline Crackers & $+0.24 \pm 0.25$ & 152 & \\
\hline Bread & $+0.99 \pm 0.29$ & 179 & \\
\hline
\end{tabular}

Analysis by Kruskal-Wallis $\mathrm{H}$ test.

hospitalisations, ${ }^{33}$ and prolonged through the pregnancy associated with a restricted diet. ${ }^{34}$ Nutrition support and nutrition requirements are top $10 \mathrm{HG}$ research priority according to a recent Priority Setting Partnership workshop report with a paucity of published literature identified. $^{35}$

To our best knowledge, this was an original study, reporting on an experiment to evaluate food items in patients with HG. Previous studies on the maternal dietary intake in NVP is by food diary, ${ }^{30}$ or questionnaire study on nausea response to food texture, type and cooking method. ${ }^{15}$ A search of PubMed was carried out on 11 August 2019 with a keyword search using the search term "hyperemesis gravidarum food" without any limits
Table 4 Secondary outcomes: participants' adverse response to food items tasted

Participants' adverse response to food item tasted ${ }^{\star}$ $(n=72)$

\begin{tabular}{ccll}
\hline & Yes† & Noł & P value§ \\
\hline Apple (Fuji) & $3(4 \%)$ & $69(96 \%)$ & 0.02 \\
Gagged & $2(3 \%)$ & & \\
Heaved & $1(1 \%)$ & & \\
Vomited & $0(0 \%)$ & & \\
Watermelon & $7(10 \%)$ & $65(90 \%)$ & \\
Gagged & $0(0 \%)$ & & \\
Heaved & $4(6 \%)$ & & \\
Vomited & $3(4 \%)$ & & \\
Cream cracker & $8(11 \%)$ & $64(89 \%)$ & \\
Gagged & $4(6 \%)$ & & \\
Heaved & $2(3 \%)$ & & \\
Vomited & $2(3 \%)$ & & \\
White bread & $12(17 \%)$ & $60(83 \%)$ & \\
Gagged & $4(6 \%)$ & & \\
Heaved & $4(6 \%)$ & & \\
Vomited & $4(6 \%)$ & & \\
\hline
\end{tabular}

Data expressed as number. ${ }^{5}$ Analysis by $\chi^{2}$ for trend.

*Participants' response in the 10 min study period after tasting the food item.

†Adverse response (increasing severity order of gagged, heaved or vomited), highest severity ascribed as participant's representative response.

$\ddagger$ No gagging, heaving or vomiting during the 10 min study period. $\S$ Analysis by $\chi^{2}$ for trend.

retrieved 89 articles; none concerned a food taste study or trial.

\section{Strengths}

With regard to the strength of our trial, we performed an original and powered study with no dropouts, and complete outcome ascertainment. The design and implementation of the trial which included the randomisation of the food taste sequence, wash-out period with mouth rinsing and small food amount alleviated the "carry-over effects' where the prior food tasted and volume of tasting might bias findings. The effectiveness of these measures was shown by comparable pretest baseline nausea scores. The four food items we trialled were widely consumed and of limited to no variability in themselves, which should cut through any ethnicity-moulded food preparation or taste allegiance, and hence support generalisability to other HG populations. Our trial protocol was demonstrably feasible in evaluating foods in HG.

\section{Limitations}

Limitations would include the post hoc use of the KruskalWallis $\mathrm{H}$ test for our rank comparisons of the four food items. Our sample size was relatively small from one centre, 
so the generalisability was limited. This trial was limited to four foods which nevertheless generated six pairwise comparisons of the primary outcome agreeability score, which was further multipliable over a number of nausearelated outcomes; nausea outcomes could be considered hypothesis generating rather than definitive. The nausea score and food agreeability scale were not validated and self-reported rather than observed. Patients or the public were not involved in the design, conduct, reporting or dissemination plans of our study. Enrolment was based on opportunistic availability of the investigator, which might lead to confounding from selection bias.

\section{CONCLUSION}

The sweet apple performed consistently well and white bread consistently poorly in a tasting trial in women with HG. In general, the fruits (apple and watermelon) were more agreeable and better tolerated compared with crackers and white bread. A therapeutic trial especially for the watermelon, which is more easily consumable in volume in acute care of hospitalised HG cases, is warranted to evaluate its effectiveness as a tolerated food to serve as the leading wedge to encourage oral intake in general as well as to provide nutrition.

Acknowledgements We thank the women who participated in the trial and all care providers for their contribution to this trial.

Contributors All authors (GNT, PCT, JGSH, KB and SZO) contributed to the design of the study. PCT conceptualised the study, GNT ran the study and collected the data, GNT, PCT and JGSH contributed equally to primary data analysis and data interpretation and codrafted the article. SZO and KB contributed to data interpretation and critically refined the article. All authors approved and asserted ownership and responsibility for the article.

Funding Internally funded by University of Malaya (Department of Obstetrics and Gynaecology). Grant number: UMSCOG/RF00102017/01.

Competing interests None declared.

Patient consent for publication Not required.

Ethics approval The trial was approved by the medical ethics committee of University Malaya Medical Centre (date of approval: 31 October 31 2017, reference number: 2017106-5653) and registered in ISRCTN registry (http://www.iscctn.com/ ISRCTN74788811) on 4 December 2017 prior to the enrolment of trial participants. The study was conducted in the gynaecology ward of the University Malaya Medical Centre, in compliance with the Declaration of Helsinki.

Provenance and peer review Not commissioned; externally peer reviewed.

Data availability statement Data are available upon reasonable request. The data are deidentified participant data.

Supplemental material This content has been supplied by the author(s). It has not been vetted by BMJ Publishing Group Limited (BMJ) and may not have been peer-reviewed. Any opinions or recommendations discussed are solely those of the author(s) and are not endorsed by BMJ. BMJ disclaims all liability and responsibility arising from any reliance placed on the content. Where the content includes any translated material, BMJ does not warrant the accuracy and reliability of the translations (including but not limited to local regulations, clinical guidelines, terminology, drug names and drug dosages), and is not responsible for any error and/or omissions arising from translation and adaptation or otherwise.

Open access This is an open access article distributed in accordance with the Creative Commons Attribution Non Commercial (CC BY-NC 4.0) license, which permits others to distribute, remix, adapt, build upon this work non-commercially, and license their derivative works on different terms, provided the original work is properly cited, appropriate credit is given, any changes made indicated, and the use is non-commercial. See: http://creativecommons.org/licenses/by-nc/4.0/.
ORCID iD

Jesrine Gek Shan Hong http://orcid.org/0000-0001-8585-2357

\section{REFERENCES}

1 Royal College of Obstetricians \& Gynecologists. The Management of Nausea and Vomiting of Pregnancy and Hyperemesis Gravidarum [Internet], 2016.

2 Hinkle SN, Mumford SL, Grantz KL, et al. Association of nausea and vomiting during pregnancy with pregnancy loss: a secondary analysis of a randomized clinical trial. JAMA Intern Med 2016;176:1621-7.

3 Royal College of OaG. The management of nausea and vomiting of pregnancy and hyperemesis gravidarum, 2016.

4 Fejzo MS, Trovik J, Grooten IJ, et al. Nausea and vomiting of pregnancy and hyperemesis gravidarum. Nat Rev Dis Primers 2019;5:62.

5 Koot MH, Boelig RC, Van't Hooft J, et al. Variation in hyperemesis gravidarum definition and outcome reporting in randomised clinical trials: a systematic review. BJOG 2018;125:1514-21.

6 Tan PC, Jacob R, Quek KF, et al. The fetal sex ratio and metabolic, biochemical, haematological and clinical indicators of severity of hyperemesis gravidarum. BJOG 2006;113:733-7.

7 Fiaschi L, Nelson-Piercy C, Tata LJ. Hospital admission for hyperemesis gravidarum: a nationwide study of occurrence, reoccurrence and risk factors among 8.2 million pregnancies. Hum Reprod 2016;31:1675-84.

8 Fiaschi L, Nelson-Piercy C, Gibson J, et al. Adverse maternal and birth outcomes in women admitted to hospital for hyperemesis gravidarum: a population-based cohort study. Paediatr Perinat Epidemiol 2018;32:40-51.

9 Gazmararian JA, Petersen R, Jamieson DJ, et al. Hospitalizations during pregnancy among managed care enrollees. Obstet Gynecol 2002;100:94-100.

10 Abas MN, Tan PC, Azmi N, et al. Ondansetron compared with metoclopramide for hyperemesis gravidarum: a randomized controlled trial. Obstet Gynecol 2014;123:1272-9.

11 Tan PC, Abdussyukur SA, Lim BK, et al. Twelve-hour fasting compared with expedited oral intake in the initial inpatient management of hyperemesis gravidarum: a randomised trial. BJOG 2020;127:1430-7.

12 Fiaschi L, Nelson-Piercy C, Deb S, et al. Clinical management of nausea and vomiting in pregnancy and hyperemesis gravidarum across primary and secondary care: a population-based study. BJOG 2019;126:1201-11.

13 Havnen GC, Truong MB-T, Do M-LH, et al. Women's perspectives on the management and consequences of hyperemesis gravidarum - a descriptive interview study. Scand J Prim Health Care 2019;37:30-40.

14 van Vliet R, Bink M, Polman J, et al. Patient preferences and experiences in hyperemesis gravidarum treatment: a qualitative study. J Pregnancy 2018;2018:1-8.

15 Tan PC, Kartik B, Thanendran P, et al. Taste, smell and food-related nausea and vomiting responses in hyperemesis gravidarum: a casecontrolled study. Sci Rep 2020;10:4445.

16 Committee on practice B-O. ACOG practice Bulletin No. 189: nausea and vomiting of pregnancy. Obstet Gynecol 2018;131:e15-30.

17 Hill AJ, Cairnduff V, McCance DR. Nutritional and clinical associations of food cravings in pregnancy. J Hum Nutr Diet 2016;29:281-9.

18 Patil CL, Abrams ET, Steinmetz AR, et al. Appetite sensations and nausea and vomiting in pregnancy: an overview of the explanations. Ecol Food Nutr 2012;51:394-417.

19 Latva-Pukkila U, Isolauri E, Laitinen K. Dietary and clinical impacts of nausea and vomiting during pregnancy. J Hum Nutr Diet 2010;23:69-77.

20 Bischoff SC, Renzer C. Nausea and nutrition. Auton Neurosci 2006;129:22-7.

21 Newman V, Fullerton JT, Anderson PO. Clinical advances in the management of severe nausea and vomiting during pregnancy. $J$ Obstet Gynecol Neonatal Nurs 1993;22:483-90.

22 and Redbridge University HospitalsBarking $\mathrm{H}$. Hyperemesis dietary advice, 2017. Available: https://www.bhrhospitals.nhs.uk/ information-and-leaflets?smbfolder $=169$

23 Jednak MA, Shadigian EM, Kim MS, et al. Protein meals reduce nausea and gastric slow wave dysrhythmic activity in first trimester pregnancy. Am J Physiol 1999;277:G855-61.

24 Einarson A, Maltepe C, Boskovic R, et al. Treatment of nausea and vomiting in pregnancy: an updated algorithm. Can Fam Physician 2007;53:2109-11. 
25 Power ML, Holzman GB, Schulkin J. A survey on the management of nausea and vomiting in pregnancy by obstetrician/gynecologists. Prim Care Update Ob Gyns 2001;8:69-72.

26 Becker DE. Nausea, vomiting, and hiccups: a review of mechanisms and treatment. Anesth Prog 2010;57:150-7. quiz 7.

27 Houghton Mifflin Co. The American heritage medical dictionary. Boston, 2007: 909.

28 Tan PC, Norazilah MJ, Omar SZ. Dextrose saline compared with normal saline rehydration of hyperemesis gravidarum: a randomized controlled trial. Obstet Gynecol 2013;121:291-8.

29 Tan PC, Khine PP, Vallikkannu N, et al. Promethazine compared with metoclopramide for hyperemesis gravidarum: a randomized controlled trial. Obstet Gynecol 2010;115:975-81.

30 Chortatos A, Haugen M, Iversen PO, et al. Nausea and vomiting in pregnancy: associations with maternal gestational diet and lifestyle factors in the Norwegian mother and child cohort study. BJOG 2013;120:1642-53.
31 Crozier SR, Inskip HM, Godfrey KM, et al. Nausea and vomiting in early pregnancy: effects on food intake and diet quality. Matern Child Nutr 2017;13. doi:10.1111/mcn.12389. [Epub ahead of print: 2911 2016].

32 The Ohio State University WMC. Hyperemesis diet (dry diet), 2018. Available: https://patienteducation.osumc.edu/Pages/search.aspx? $\mathrm{k}=$ hyperemesis+diet

33 Tan PC, Jacob R, Quek KF, et al. Readmission risk and metabolic, biochemical, haematological and clinical indicators of severity in hyperemesis gravidarum. Aust N Z J Obstet Gynaecol 2006;46:446-50.

34 Mullin PM, Ching C, Schoenberg F, et al. Risk factors, treatments, and outcomes associated with prolonged hyperemesis gravidarum. $J$ Matern Fetal Neonatal Med 2012;25:632-6.

35 Dean $\mathrm{CR}$, Bierma H, Clarke R, et al. A patient-clinician James Lind alliance partnership to identify research priorities for hyperemesis gravidarum. BMJ Open 2021;11:e041254. 